\title{
A SOFTWARE APPLICATION TO OBTAIN THE DEPTH OF CLOSURE FROM BEACH PROFILE DATA
}

\author{
J.I. PAGÁN ${ }^{1}$, Y. VILLACAMPA ${ }^{2}$, L. ARAGONÉS ${ }^{1}$ \& I. LÓPEZ ${ }^{1}$ \\ ${ }^{1}$ Dept. of Civil Engineering. University of Alicante, Spain. \\ ${ }^{2}$ Department of Applied Mathematics. University of Alicante, Spain.
}

\begin{abstract}
The depth of closure of the beach profile, from now on termed as DoC, is a key parameter to perform effective evaluations of beach nourishments or coastal defence works. It is defined for a given time interval, as the closest depth to the shore at which there is no significant change in seabed elevation and no significant net sediment transport between the nearshore and offshore. To obtain this point it is necessary to compare profile surveys at a given period of time, and evaluate them to find the point in the profile where the depth variation is equal to, or less than, a pre-selected criteria. In order to manage all this information, a software application has been developed. On providing the input of the beach profiles, this tool offers the possibility of selecting the dates of the desired period of study, graph the profiles and then obtain, for each XY coordinate, all the required parameters, such as offshore distance, maximum, average and minimum depth, standard deviation and area difference between profiles. By evaluating each point along the profile, the DoC can be obtained at that point that meets the criteria. Moreover, this tool allows to graph not only the initial and final profile of the period, but all the beach profiles recorded, creating its maximum and minimum envelope. In addition, if the user introduces the parameters related to the equilibrium beach profile, this tool also corrects the area difference, taking into account the morphological changes (erosionaccretion) that may have occurred during the period studied. In conclusion, this tool has a friendly interface for obtaining the DoC with accuracy by interactive selection of the period of study. It also stores all the information and exports it to different formats.

Keywords: beach profile, depth of closure, software tool.
\end{abstract}

\section{INTRODUCTION}

A key element in beach morphodynamics is the Depth of Closure (DoC). This concept is used in coastal engineering as an empirical measurement of the seaward limit of cross-shore sediment transport in sandy beaches. It is defined, for a given time interval, as 'the most landward depth of which there is no significant change in bottom elevation and no significant net sediment transport' Kraus et al. [1]. Also, Nicholls et al. [2] distinguish two zones with different levels of morphodynamic activity, separating a landward active zone from a seaward less active zone over the period defined by the profile observations. The DoC is the boundary between these zones.

The applications of this concept in coastal engineering are several and highlight the importance of the adequate knowledge of this morphodynamic limit, such as: i) coastal sediment budget analysis, Hands [3]. ii) The delimitation of the active region to identify sand borrow sites, Hands and Allison [4]. iii) Numerical modelling of coastal changes, Kraus and Harikai [5] or iv) Beach fill design and planning for defence structures (groins or breakwaters), Avila-Serrano et al. [6]. 
There are two methods that are mainly used to obtain the DoC. Firstly, those that obtain this limit from analytic or predictive formulas, all of which are derived from the initial formula proposed by Hallermeier [7]. Secondly, the most widely used method is based on the comparative study of repetitive profile surveys over a given period of time. Beach profiles are an important indicator, since they allow to reconstruct the morphology of the region, as well as to infer the volume of sediment that is eroded or deposited in a certain time.

Such profiles define an envelope of variation which declines with depth. The DoC is settled as the depth beyond which seabed changes are 'not significant', Nicholls et al. [2]. To calculate this place the criteria described by Hinton and Nicholls [8], the Fixed depth change (FDC) criterion and the Standard deviation of depth change (SDDC) can be used. FDC defines the DoC as that point at which, for two profiles from the same location, the depth variation is equal to, or less than, a pre-selected criteria. The criteria values are usually related to the measurement errors of the profile survey. SDDC is equated to that point at which the standard deviation reaches a constant, non-zero tail, which often has a value of the measurement accuracy. The envelope is commonly generated using only the initial and final profiles of the period of study. In this paper, this method is named as the Initial Final Method (IFM). When all the available profiles in the period are used to create the envelope, the method is named Envelope Method (EM).

Besides, the morphological evolution of a beach over the years is characterized by both cross-shore and longshore changes. The equilibrium beach profile (EBP) represents the morphology of the most frequent profile over a long period. This knowledge in the long term is important for interpreting natural beach processes and for many coastal engineering applications, such as the erosion-accretion movements of the shoreline or the design of beach fills projects. Indeed, its lower limit is the DoC, Aragonés et al. [9].

In conclusion, to know the position of the DoC the coastal engineer must evaluate multiple beach profiles over a long period of time, generating the envelope of these profiles and locating the point where the established criterion is met. In addition, it is necessary to incorporate to this analysis the morphological changes that may have occurred during the period studied. This process requires handling a large amount of data, as well as the plot of the envelopes and evaluating each point to check if the conditions are met to be the DoC. The software application we present in this paper has been developed to help in this arduous task. The user can load and select the beach profiles available dynamically, generating the envelope for diverse periods of time, evaluating and storing the information of the points identified as DoC. With its friendly interface, this tool makes the analysis of the repetitive beach profile surveys easier and, thereby, the study of the position of the DoC.

\section{THE TOOL INTERFACE}

This application has been developed from a spreadsheet, which has been improved through the automation of complex tasks. This spreadsheet has been created with Microsoft ${ }^{\circledR}$ Excel ${ }^{\circledR}$ 2013, which includes Visual Basic for Applications (VBA). By using programmable controls in the worksheet it has been possible to give a new dimension to the traditional use of spreadsheets, being able to create different scenarios or interact with graphic dynamically. The tabs of the tool and its features are described in the following paragraphs.

\subsection{Beach profile tab}

The application starts in this tab, where the beach profiles are added. Using the Load Profiles button the file which contains the elevation data can be selected. It works with the following 
extensions: .txt, .xls and .csv. Profile data must be grouped in two columns, the first one referring to the coordinate $\mathrm{X}$, measuring distance from the origin, and the second one containing the heights. In order to identify the period of study, the heading of each column must contain the date of the profile survey.

Once the profile data has been loaded, it is possible to select one, some or all the beach profiles available by means of a select control, and plot them. A displacement control has been introduced into the window so that the user can know, for any entered distance, the elevation in each profile. The height is calculated by linear interpolation from the two points closest to the entered distance, so the result will be more accurate if the precision of the profile survey is high (short distance between points). In the summary pop-up, the maximum and minimum height for the position entered is displayed, identifying those profiles which causes it, as well as the average depth, the difference between the maximum and minimum profiles and the standard deviation (Fig. 1).

The window has the buttons IN y Zoom OUT, Show All y Clean All profiles showed, Print and Export the plot to different formats (.png, .jpg and .pdf). The Sandbar Analysis button opens a new window that allows the user to select a period of time, graph the profile and identify the position of the sandbar o sandbars on it. The start position, the crest, the end and the width of the sandbar are saved, up to a maximum of three sandbars per profile. It also has a button to generate the list with the position of each of the sandbars for each date (Fig. 2)

\subsection{Depth of closure tab}

This is the main tab of the application. It contains all the necessary elements for the analysis of the DoC from beach profiles at different periods of time. It is shown in Fig. 3, and its description identifies four parts discussed in the following paragraphs.

\subsubsection{Ribbon (A)}

First, the profile name is identified and the period is studied. Below, the number of years covered by the period and the number of profiles used to generate the envelope, which depends on the method chosen to calculate the DoC is displayed. Next, it is the period

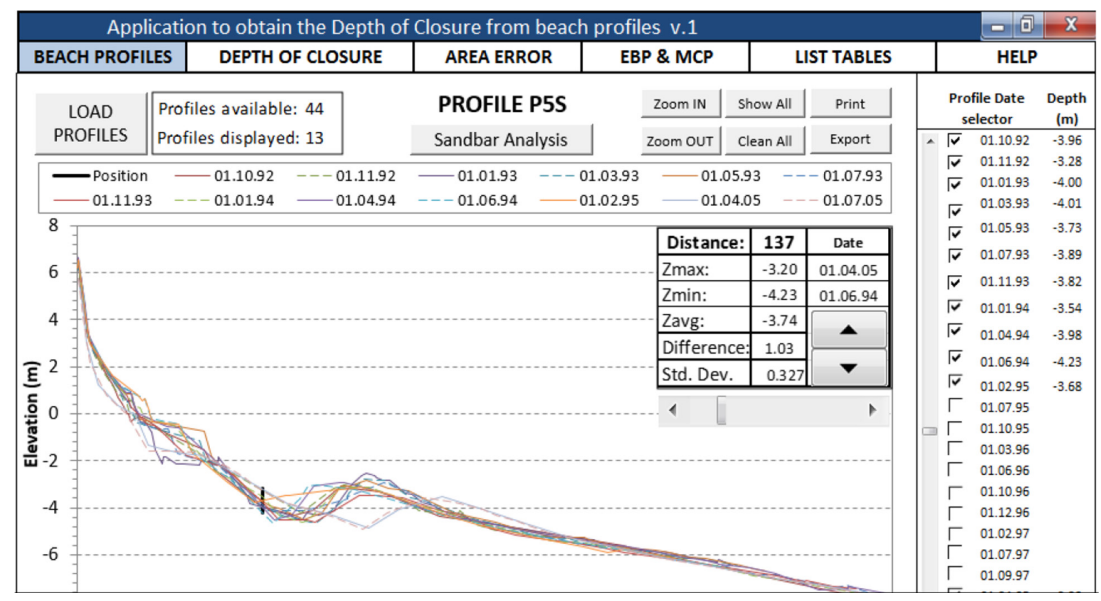

Figure 1: Beach profiles tab. 


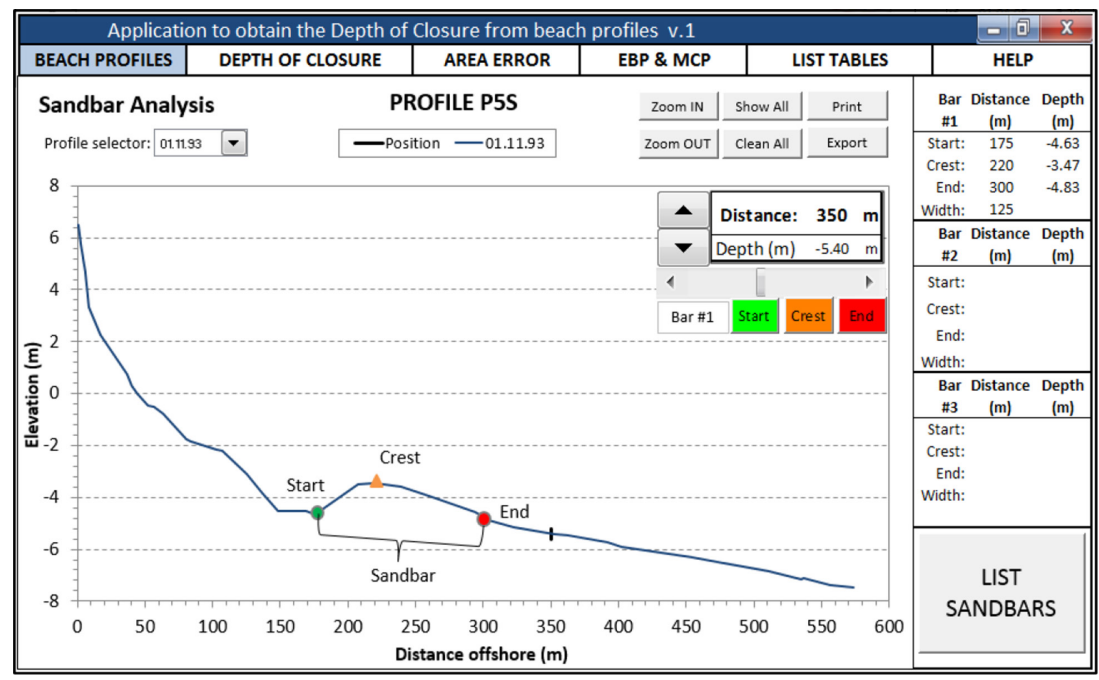

Figure 2: Sandbar Analysis window.

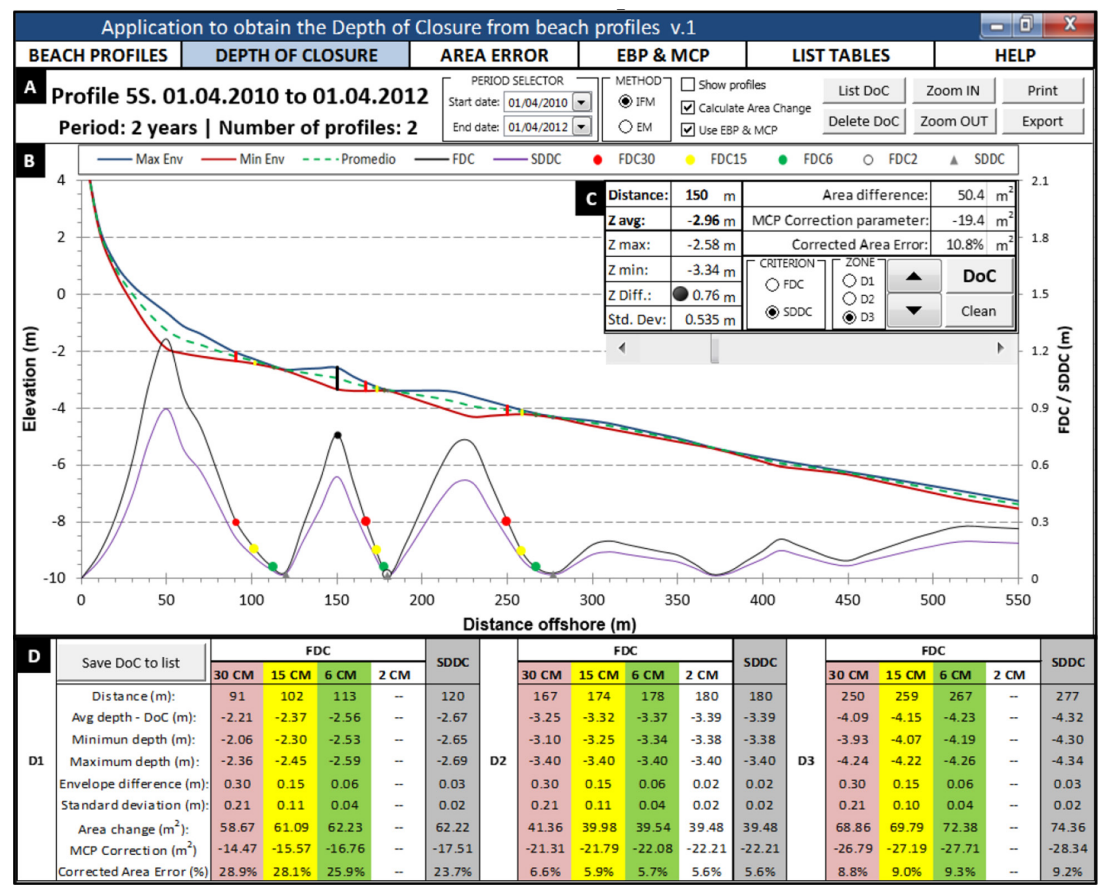

Figure 3: Depth of closure tab.

selector, where the user can select any profile surveyed by its date. By choosing the initial and final dates the application plots the envelope dynamically, and thus can easily generate multitude of periods of study within the available range of dates. The method for making the envelope is chosen then. The IFM is predefined, but the user can choose the EM if it wants to use all available profiles within the period selected. The additional options are related to show 
the profiles that forms the envelope, if the area error is calculated and if the user wants that the area error would be corrected morphologically. These options are detailed in the following sections. Finally, there are the usual buttons Zoom In, Out, Print and Export and controls to list all DoC obtained or delete the selected period.

\subsubsection{Plot area (B)}

This area of the screen is where graphs are drawn. The $\mathrm{X}$-axis shows the offshore distance from profile pole and the Y-axis the elevation. Maximum, average and minimum envelope are plotted, as well as the evolution of the difference between envelopes, associated to the FDC criteria, and the standard deviation related to the SDDC. It also plotted the cursor position in its advance along the profile and the position of each candidate point for DoC for each of the criteria, identified by its symbols. If the checkbox of Show profiles is on, all the beach profiles of the period are plotted (Fig. 4). It also shows the legend with the color coding of each criterion to obtain the DoC.

\subsubsection{Data display (C)}

The Data display window provides a dynamic display of all parameters that this application calculates. Thus, for any distance entered, the average depth of the envelope (that it will be the DoC when the selected criteria are met), the maximum and minimum depth, the difference between envelopes (identifying which FDC criterion is met by its colour code) and the standard deviation of the depth are displayed. It also has the controls for the displacement along the profile and the storage of the DoC candidate points. In order to classify the multiple points that would probably meet the criteria, the profile display has been divided into three zones, an initial, middle and final, called D1, D2 and D3, respectively. The DoC button

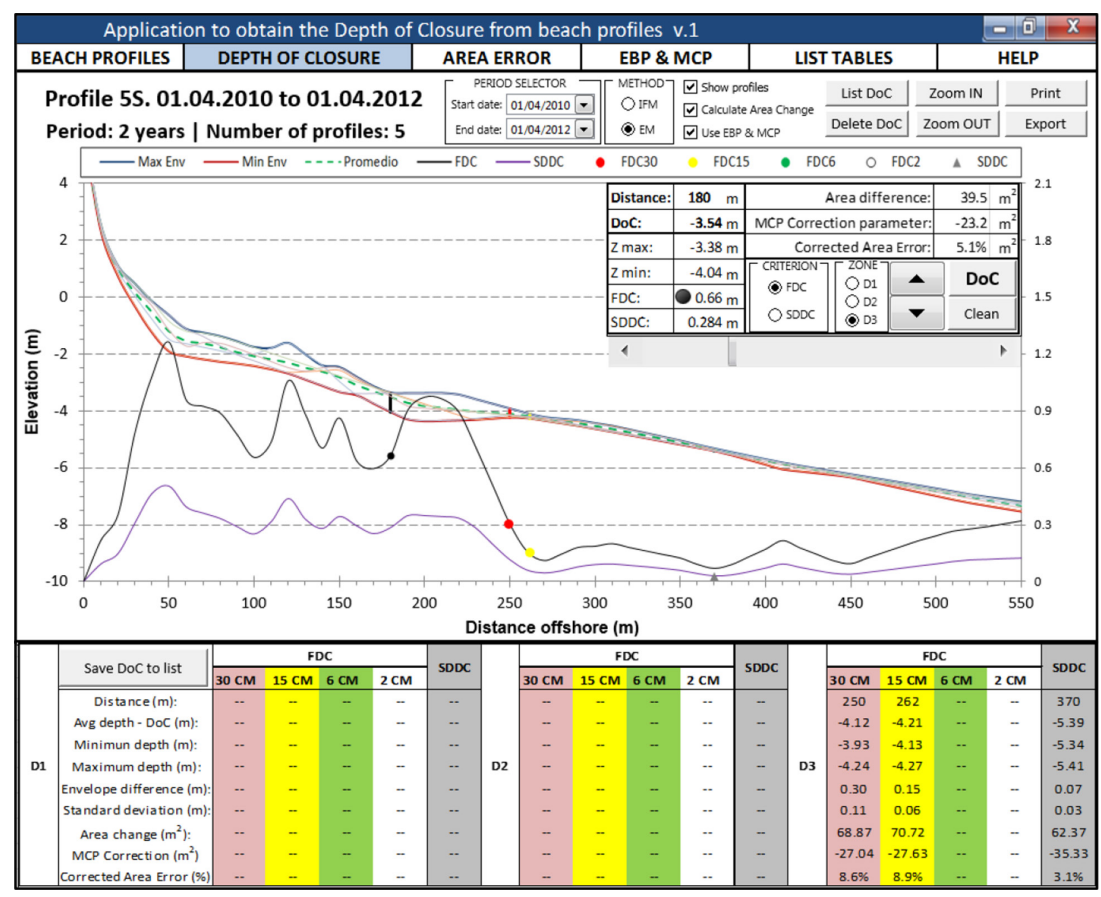

Figure 4: EM with profiles plotted. 
saves the data according to the criteria and zone selected, while the Clean button erases them. Also displayed are the results of the area difference between the profiles of the period (related to the cross-shore sediment transport) and the morphological correction of the area difference if their respective checkboxes are ticked. These parameters are explained in Sections 2.3 and 2.4 .

\subsubsection{Data storage of the candidate points to DoC (D)}

Finally, at the bottom of the window the screen shows the data of each point saved as a candidate to be the DoC, classified by its zone along the profile. It is a button to bring these data, which are only for the selected period, to the list of all the period studied.

\subsection{Area Error tab}

The DoC is defined as 'the most landward depth of which there is no significant change in bottom elevation and no significant net sediment transport'. In order to study the second part of the definition, the area difference for each period between the start point of each profile (common to all of them) and each of the DoCs obtained by the methods described in the previous section has been calculated.

To calculate this area change between profiles (Fig. 5), the spreadsheet has been scheduled to get the area under the initial and final profiles of the period of the study selected. These areas are calculated using the trapezoid method in intervals of $1 \mathrm{~m}$ between the distance $\mathrm{x}=0$ and $x=$ ' $x$ ' equal to the distance where the DoC is placed. In order to obtain positive values always, the $\mathrm{X}$-axis is displaced a distance ' $\mathrm{y}$ ' equal to the value of the $\mathrm{DoC}$, so that the area is the result of the defined integral between the profile and the baseline $y=\mathrm{DoC}$. The difference of the areas of the initial and final profiles of the period gives the cross-shore net sediment transport, as stated by Kraus et al. [1].

\subsection{EBP \& MCP tab}

When significant changes in the shoreline occurs, it is mandatory to correct the area error previously calculated to avoid misinterpreting the sediment transport. By means of the EBP

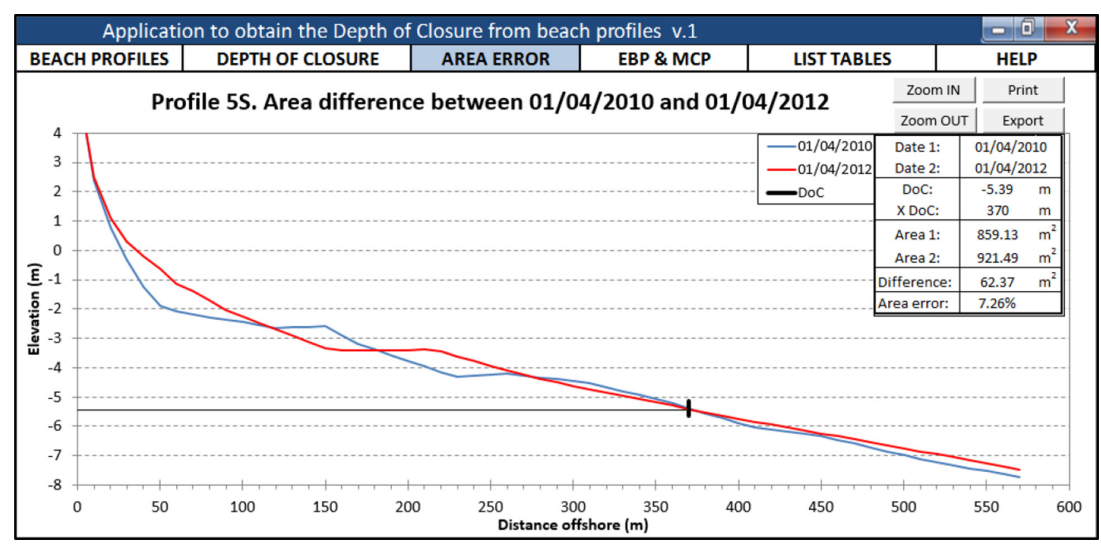

Figure 5: Area error tab. 
this parameter is corrected. Dean [10] exposed the potential function (1) that is most used in coastal engineering.

$$
y(x)=A \cdot x^{2 / 3}
$$

where $y$ corresponds to the theoretical profile depth according to distance to shoreline $x$ and $A$ is a parameter known as a scale factor. To correct the area error, the EBP of the studied beach is used, characterized by its A parameter that has to be typed by the user. Then the EBPs are plotted taking as the origin point the position of the shoreline at the initial and final dates of the period of study (Fig. 6). Next, the area difference between both profiles are obtained, taking as integer limits the shoreline $(\mathrm{y}=0)$ and the DoC as baseline $(\mathrm{y}=\mathrm{DoC})$. The result is named as Morphological Correction Parameter, MCP. If during the period of study an accretion has occurred, the MCP will be negative. On the contrary, if there was an erosion, the MCP will be positive. Finally, to obtain the corrected area error the value of the MCP will be added to the value of the area error obtained as it was described in Section 2.3. In order to compare the results the corrected area error is finally evaluated in absolute value, as the DoC definition only considers the net sediment transport and not its movement offshore or onshore. Including this parameter to the analysis of the DoC gives the coastal engineer a measurement of the cross-shore sediment transport during the period studied.

A chart is also generated in this window, graphing the beach width (from the beach pole to the shoreline) for each available date.

\subsection{List tables tab}

In this tab, the list of all points marked as candidate to DoC are shown. Each row of this table means a point saved as DoC in the tab Depth of Closure. The table has 27 columns, each one storing a parameter (Table 1). Two different lists for each methods, IFM and EM, are created. These lists can be exported for further statistical analysis.

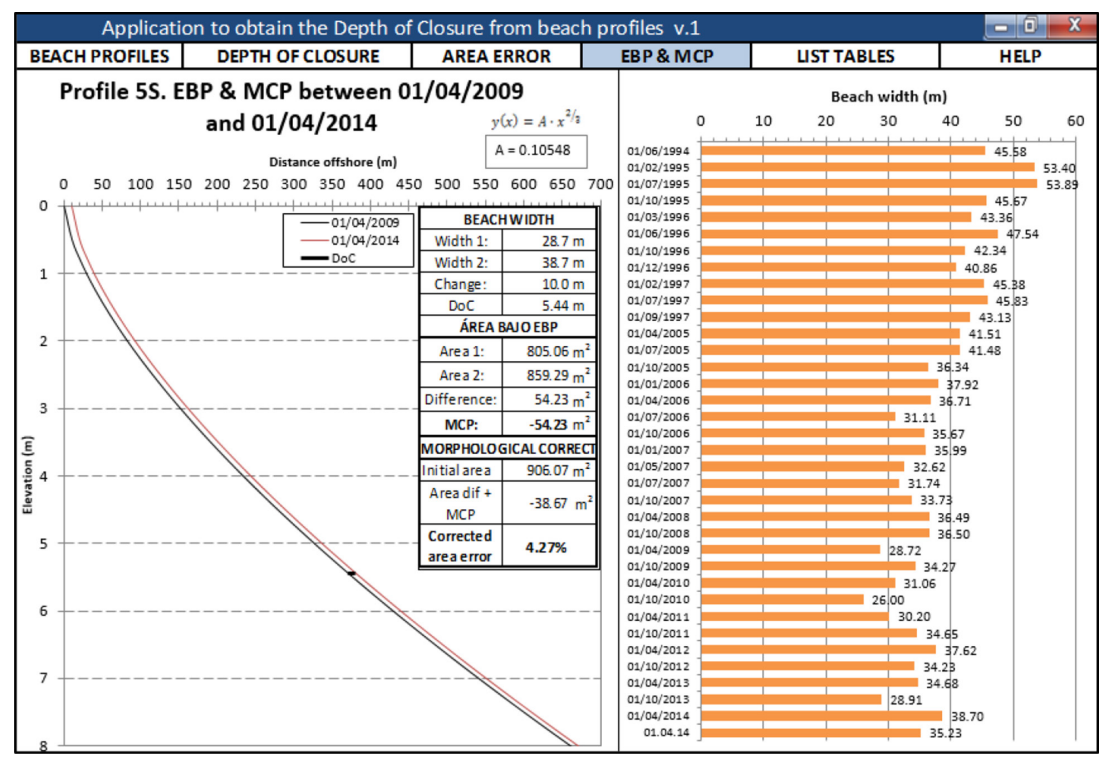

Figure 6: EBP \& MCP tab. 
Table 1: List table column headings.

\begin{tabular}{lll}
\hline Period of study & Distance $(\mathrm{m})$ & Area error $(\%)$ \\
\hline ID Profile & DoC $(\mathrm{m})$ & Initial beach width $(\mathrm{m})$ \\
Period (years) & Z maximum $(\mathrm{m})$ & End beach width $(\mathrm{m})$ \\
Initial Date & Z minimum $(\mathrm{m})$ & Beach width change $(\mathrm{m})$ \\
End Date & Envelope difference $(\mathrm{m})$ & ABS Beach change $(\mathrm{m})$ \\
Season (Winter/Summer) & Standard deviation $(\mathrm{m})$ & $\mathrm{MCP}\left(\mathrm{m}^{3} / \mathrm{m}\right)$ \\
Zone (D1|D2|D3) & Initial area $\left(\mathrm{m}^{3} / \mathrm{m}\right)$ & Corrected Area error $\left(\mathrm{m}^{3} / \mathrm{m}\right)$ \\
Method (IFM/EM) & End Area $\left(\mathrm{m}^{3} / \mathrm{m}\right)$ & ABS Corrected error $\left(\mathrm{m}^{3} / \mathrm{m}\right)$ \\
Criterion (FDC/SDDC) & Area difference $\left(\mathrm{m}^{3} / \mathrm{m}\right)$ & Corrected Area error $(\%)$ \\
\hline
\end{tabular}

\subsection{Help tab}

In this tab, the definitions of each parameter and the instructions of the different tools are shown.

\section{CASE STUDY}

An example of the use of this application is presented in this section. A coastal engineer has 44 profile surveys of a certain beach, called P5S, all taken from the same point of origin with a time period spanning 22 years. The engineer intends to know the DoC of this beach at different time scales, in order to design a beach fill project. In addition, he intends to assess whether the differences between applying a fixed criterion of $30 \mathrm{~cm}$ or $2 \mathrm{~cm}$ is preferred or if it is better to use a method based on the standard deviation of multiple profiles.

\subsection{Step one, load profiles and sandbar analysis}

Firstly, the available profiles are loaded from a .txt file using the Beach Profiles tab. Once plotted, it can be observed that the profiles cover a distance of $600 \mathrm{~m}$ offshore and reach a depth of $8 \mathrm{~m}$ (Fig. 1). An active area of sandbars is also detected. In order to analyse this, through the button Sandbar Analysis the user selects each profile one by one and marks the position of the sandbars. For the period November 1993, the first bar is located at $100 \mathrm{~m}$ offshore and $1 \mathrm{~m}$ depth and the second one at $250 \mathrm{~m}$ and $3.5 \mathrm{~m}$ depth (Fig. 2). This process is repeated for all the profiles, and will help to distinguish the candidate points to DoC.

\subsection{Step two, obtaining the DoC}

The second step is the analysis of the DoC. For this purpose, multiple periods of study from available profiles will be generated, ranging from 1 year to more than 20 years. As example, the period from $01 / 04 / 2010$ to $01 / 04 / 2012$ is shown. Using the displacement controls the user moves forward along the profile, saving the points that meet the criteria of DoC (Fig. 3). Next to this all the information of the points are saved to the list and the graph is exported to .pdf. The process is repeated applying the EM method for the same period (Fig. 4). In this case, the envelope is created using the five beach profiles available during this two-year period. Candidate points to DoC is only obtained in the zone D3. As the checkboxes of Calculate area error and Use EBP \& MCP are ticked, these parameters related to the 
measurement of the net cross-shore sediment transport are calculated for each point marked as DoC.

\subsection{Step three, analysis of the data obtained}

Once the user has repeated this process with all the available periods, it goes to the List tab and exports the tables for its statistical analysis. In this case, a total of 150 periods of time have been generated. A number of 1,100 candidate points to DoC for the different criteria have been stored using the IFM method, whereas only 700 were obtained by the EM method. The analysis of its position, together with the sandbars, identifies those points located within the zone D3 as true DoC, since it is revealed as the zone outside the movement of sandbars. The area error in this zone is lower than $10 \%$, which means that the cross-shore net sediment transport is not significant.

Regarding the period of study, the engineer noticed that the DoC increases as the period is longer. For periods of more than 10 years, the DoC is located at $6 \mathrm{~m}$ depth. More significant is the difference between criteria, with differences of more than $1 \mathrm{~m}$ depth between FDC $30 \mathrm{~cm}$ and FDC $2 \mathrm{~cm}$, which means an almost $100 \mathrm{~m}$ length. These differences mean an increase in the sand volume required to the beach-fill project, and thus an increase in the cost of the works. Finally, after analysis of all the data, the DoC used for the project is the one obtained by the method EM, criterion SDDC and period longer than 10 years. Its coordinates are $5.85 \mathrm{~m}$ depth, $395 \mathrm{~m}$ offshore.

\section{CONCLUSIONS}

To obtain the DoC with adequate precision, the coastal engineer has to deal with a multitude of beach profiles over an extended period of time, plot them, generate the envelope and locate the point where the established criteria is met. Moreover, it is necessary take into account the morphological changes that may have occurred during the period studied. This application has been developed with the aim of helping in this hard task. It provides several tools to aid in graphical exploration of profile plots, allowing him to load and select dynamically beach profiles for different periods of time, evaluating and storing the information of the candidate points for DoC. Together with the analysis of the sandbars and the morphological corrections, the real DoC can be obtained with precision. And what is more, this tool facilitates the creation and export of listings of the data and graphs for its presentation on researches and reports, as well as for its statistical treatment. With its friendly user interface, this application has become a very useful tool for the coastal engineer.

\section{ACKNOWLEDGEMENTS}

This research has been partially funded by Universidad de Alicante through the project 'Estudio sobre el perfil de equilibrio y la profundidad de cierre en playas de arena' (YGRE15-02).

\section{REFERENCES}

[1] Kraus, N.C., Larson, M. \& Wise, R.A., Depth of closure in beach-fill Design. Coastal Engineering Technical Note CETN II-40, 3/98, U.S. Army Engineer Waterways Experiment Station, Vicksburg, MS, 1998.

[2] Nicholls, R.J., Birkemeier W.A. \& Hallermeie, R.J., Application of the Depth of Closure concept. 25th International Conference on Coastal Engineering. American Society of Civil Engineers, Reston, VA, pp. 3874-3887, 1996. 
[3] Hands, E.B., The great lakes as a test model for profile responses to sea level changes. In Handbook of Coastal Processes and Erosion, C.R.C. Press: Boca Raton, Florida, pp. 176-189, 1983.

[4] Hands, E.B. \& Allison, M.C., Mound migration in deeper water and methods of categorising active and stable depths. Proceeding of the ASCE Specialty Conference on Quantitative Approaches to Coastal Sediment Processes, Seattle, Washington, Vol. 2, 1985-1999, 1991.

[5] Kraus, N.C. \& Harikai, S., Numerical model of the shoreline change at Oarai beach. Coastal Engineering, 7, pp. 1-28, 1983. https://doi.org/10.1016/0378-3839(83)90024-8

[6] Avila-Serrano, G.E., Santa Rosa del Río, M.A., Anfuso-Melfi, G., Benavente-González, J., Guardado-France, R., González-Yajimovich, O. \& Velázquez-González, E.K., Sediment variations and littoral transport at La Victoria Beach, Cádiz, Spain. Ciencias Marinas, 35(3), pp. 259-269, 2009.

[7] Hallermeier, R.J., A profile zonation for seasonal sand beaches from wave climate. Coastal Engineering, 4, pp. 253-277, 1980. https://doi.org/10.1016/0378-3839(80)90022-8

[8] Hinton, C. \& Nicholls, R.J., Spatial and temporal behaviour of depth of closure along the holland coast. International Conference on Coastal Engineering, American Society of Civil Engineers, Reston, VA, pp. 2913-2925, 1998.

[9] Aragonés, L., Serra, J.C., Villacampa, Y., Saval, J.M. \& Tinoco, H., New methodology for describing the equilibrium beach profile applied to the Valencia's beaches. Geomorphology, 259, pp. 1-11, 2016.

https://doi.org/10.1016/j.geomorph.2015.06.049

[10] Dean, R.G., Equilibrium beach profiles: US Atlantic and Gulf coasts, Department of Civil Engineering and College of Marine Studies, University of Delaware, 1977. 